\title{
Impact of hyperoxemia on mortality in critically ill patients with ventilator-associated pneumonia
}

\author{
Sophie Six ${ }^{1,2}$, Anahita Rouzé ${ }^{1}$, Olivier Pouly ${ }^{1,2}$, Julien Poissy ${ }^{1,2}$, Frédéric Wallet ${ }^{3}$, Sébastien Preau ${ }^{1}$, Saad \\ Nseir $^{1,2}$ \\ ${ }^{1} \mathrm{CHU}$ Lille, Centre de Réanimation, Lille, France; ${ }^{2}$ Univ. Lille, Faculté de Médecine, Lille, France; ${ }^{3} \mathrm{CHU}$ Lille, Centre de Biologie-Pathologie, \\ Lille, France \\ Contributions: (I) Conception and design: S Six, S Nseir; (II) Administrative support: None; (III) Provision of study materials or patients: All authors; \\ (IV) Collection and assembly of data: All authors; (V) Data analysis and interpretation: All authors; (VI) Manuscript writing: All authors; (VII) Final \\ approval of manuscript: All authors. \\ Correspondence to: Prof. Saad Nseir. CHU Lille, Centre de Réanimation, F-59000 Lille, France. Email: s-nseir@chru-lille.fr.
}

Background: The objective of this study was to assess the impact of hyperoxemia on mortality in critically ill patients with ventilator-associated pneumonia (VAP).

Methods: This observational study was performed in a 50-bed mixed intensive care unit (ICU) during a 1-year period. Quantitative microbiological confirmation was required for VAP diagnosis. Hyperoxemia was defined as peripheral capillary oxygen saturation $\left(\mathrm{SpO}_{2}\right) \geq 98 \%$. $\mathrm{SpO}_{2}$ was hourly collected in all study patients during the whole period of mechanical ventilation. The primary objective was to assess the influence of hyperoxemia on ICU mortality.

Results: Ninety-three patients with VAP were all included in this study. ICU-mortality rate was $32 \%$ (30 of 93 patients). The mean percentage of time spent with hyperoxemia in survivors and nonsurvivors at ICU admission, before, after or at the time of VAP diagnosis was not significantly different. Multivariate analysis identified age, and sequential organ dysfunction assessment at the day of VAP occurrence as independent risk factors for ICU mortality [odds ratio $(\mathrm{OR})=1.04$ (95\% CI, 1.01-1.08) per year, $\mathrm{P}=0.019 ; 1.19$ (95\% CI, 1.06-1.34) per point, $\mathrm{P}=0.003$; respectively]. The time spent with hyperoxemia before VAP occurrence was not significantly associated with mechanical ventilation free days, or ICU length of stay.

Conclusions: Hyperoxemia at ICU admission, or during ICU stay, had no significant impact on ICU mortality in critically ill patients with VAP.

Keywords: Hyperoxemia; ventilator-associated pneumonia (VAP); mortality; critical illness; mechanical ventilation $(\mathrm{MV})$

Submitted Aug 28, 2018. Accepted for publication Oct 05, 2018.

doi: $10.21037 /$ atm.2018.10.19

View this article at: http://dx.doi.org/10.21037/atm.2018.10.19

\section{Introduction}

Oxygen is commonly used in critically ill patients (1). Several studies clearly demonstrated that oxygen was frequently used beyond patients' needs and that hyperoxemia was common in the intensive care units (ICU) (2-4). However, the safety of hyperoxemia has been recently challenged (5). A strategy based on liberal oxygen treatment is meant to avoid hypoxia and increase the oxygen supply to the different suffering organs. However, this excessive supply is not safe and could generate harm via the production of reactive oxygen species (ROS). High concentrations of stress-mediated ROS can lead to cellular necrosis and apoptosis (6). Further, hyperoxemia induces vasoconstriction, and decreases cardiac output which reduces blood flow and ultimately oxygen transport $(5,7)$. The process of oxidative stress could result in multiorgan failure (8). The association between mortality and hyperoxemia was also reported by retrospective 
studies performed in different patient populations (9-11). In mechanically ventilated patients, the results of available studies on the relationship between mortality and hyperoxemia are controversial. A recent prospective study (12) evaluated the impact of conservative versus conventional oxygen therapy on mortality in ICU patients. The authors concluded that reaching a conservative oxygenation target [arterial oxygen tension $\left(\mathrm{PaO}_{2}\right)$ between 70 and $100 \mathrm{mmHg}$, or peripheral oxygen pulse saturation $\left(\mathrm{SpO}_{2}\right)$ values between $94 \%$ and $98 \%$ ] resulted in decreased ICU-mortality, but the rate of patients with ventilatorassociated respiratory infections was similar in the two groups.

The pathophysiology of pulmonary lesions resulting from hyperoxemia has clearly been described in animal studies $(13,14)$. Hyperoxic acute lung injury (HALI) was reported to by previous studies. Some mechanisms responsible for HALI are similar to those of acute respiratory distress syndrome (ARDS) $(15,16)$. Complications of hyperoxemia, such as acute lung injury, atelectasis, and decreased clearance of bacteria could be associated with the development of ventilator-associated pneumonia (VAP) (17). Entezari et al. (18) demonstrated that exposure to hyperoxemia for a long period of time reduced the capacity of macrophages in phagocytosing Pseudomonas aeruginosa. Another study reported high mortality rates in mice infected with $P$. aeruginosa and exposed to hyperoxemia (19). Recently, we performed a retrospective analysis of prospectively collected data in a cohort of 503 patients receiving mechanical ventilation (MV) for $>48 \mathrm{~h}(20)$. The multivariate analysis identified hyperoxemia as an independent risk factor for VAP odds ratio $(\mathrm{OR})=1.1$ [95\% confidence interval $(\mathrm{CI})$, 1.04-1.2] per day, $\mathrm{P}=0.004\}$.

To our knowledge, no clinical study has assessed the impact of hyperoxemia on mortality in patients with VAP. However, patients with VAP have located or diffuse alveolar damage, and could be at higher risk for mortality in presence of hyperoxemia. Our hypothesis was that in patients with VAP, hyperoxemia could be associated with higher ICU-mortality rates. Therefore, we conducted this single-center retrospective study to investigate the influence of hyperoxemia on ICU mortality, and morbidity in patients with VAP.

\section{Methods}

\section{Study characteristics}

This study was performed in a 50-bed mixed ICU, at the university hospital of Lille, France, from January 2016 to January 2017. The IRB of the Lille University Hospital approved the study and waived informed consent. In accordance with the French law, and because of the retrospective observational design, written informed consent was not required.

All data were retrospectively collected. All patients with VAP were included in this study. Only first VAP episodes were investigated.

\section{Definitions}

VAP was defined as the presence, $>48 \mathrm{~h}$ after starting invasive $\mathrm{MV}$, of new or progressive pulmonary infiltrate, and at least two of the following criteria: (I) fever $\left(\geq 38^{\circ} \mathrm{C}\right)$ or hypothermia $\left(\leq 36^{\circ} \mathrm{C}\right)$; (II) leukocytosis $\left(\geq 11 \times 10^{9} / \mathrm{L}\right)$ or leukopenia $\left(<3.5 \times 10^{9} / \mathrm{L}\right)$, and (III) purulent respiratory secretions (21). Microbiological confirmation was required in all patients [positive bronchoalveolar lavage $\geq 10^{4}$ colony forming unit per milliliter (CFU/mL), or positive tracheal aspirate $\left.\geq 10^{5} \mathrm{CFU} / \mathrm{mL}\right]$. VAP was considered as early-onset when it was diagnosed before the fifth day, and late-onset when it was diagnosed the fifth day or later, after starting MV (21).

The following microorganisms were defined as multidrug-resistant bacteria (MDRB): ceftazidime or imipenem-resistant $P$. aeruginosa, $\beta$-lactamase-producing Gram-negative bacilli, imipenem-resistant Acinetobacter baumannii, and methicillin-resistant Staphylococcus aureus.

Hyperoxemia was defined as peripheral oxygen saturation $\left(\mathrm{SpO}_{2}\right)$ values $\geq 98 \%$. In all patients, one measurement per hour was prospectively and automatically collected, during the whole period of invasive MV. The daily percentage of time spent with hyperoxemia was calculated as the number of hours with hyperoxemia divided by 24 . For example, a patient who spent $6 \mathrm{~h}$ with hyperoxemia per day had a percentage of $25 \%(6 / 24)$.

Prior antibiotic use was defined as antimicrobial treatment during the three months preceding ICU admission. Antibiotic treatment was considered appropriate when at least one antibiotic active in vitro on all organisms causing VAP was administrated to treat VAP. Antibiotic treatment for patients with suspected VAP was based on ATS/IDSA guidelines (21).

The primary objective was to determine the impact of hyperoxemia on ICU mortality. Secondary objective was to determine the impact of hyperoxemia on duration of $\mathrm{MV}$, mechanical-ventilation free days, sepsis related organ failure 
assessment (SOFA) score at VAP occurrence, and length of ICU stay.

\section{Study patients}

A VAP prevention strategy was routinely used during the study period. No written guidelines regarding oxygen therapy were used in the ICU during the study period.

\section{Data collection}

All data were retrospectively recorded from January $1^{\text {st }}$, 2016 to January $1^{\text {st }}$, 2017. The followings characteristics were recorded at ICU admission: age, male gender, severity of illness based on simplified acute physiology score (SAPS) II, and SOFA score; comorbidities [diabetes, chronic obstructive pulmonary disease (COPD), chronic heart failure, cirrhosis, chronic renal failure requiring dialysis, immunosuppression], location before ICU admission, admission category (medical or chirurgical), cause of ICU admission, $\mathrm{PaO}_{2}, \mathrm{FiO}_{2}$, and percentage of time spent with hyperoxemia during the first $24 \mathrm{~h}$. During ICU stay, the following data were collected: daily percentage of time spent with hyperoxemia $\left(\mathrm{SpO}_{2} \geq 98 \%\right)$, number of days from starting invasive $\mathrm{MV}$ to VAP occurrence, clinical pulmonary infection score (CPIS) and SOFA score at the day of VAP diagnosis, MV duration, microbiological results, appropriateness of antimicrobial and its duration, and ICU mortality. All data were collected from ICU admission until death or ICU discharge.

\section{Statistical analysis}

SPSS software (SPSS, Chicago, IL, USA) was used for data analysis. Categorical variables were described as frequencies (\%). The distribution of continuous variables was tested for normality. Normally and skewed continuous variables were described as mean $\pm \mathrm{SD}$, or median and interquartile range (IQR), respectively. All $\mathrm{P}$ values were two-tailed. Differences were considered significant if $\mathrm{P}$ values were $<0.05$.

In order to determine factors associated with mortality, survivors were compared with nonsurvivors using bivariate and multivariate analyses. The $\chi^{2}$ test or Fischer's exact test were used to compare qualitative variables, as appropriate. Student's $t$-test or the Mann-Whitney U-test were used to compare continuous variables, as appropriate. All variables from univariate analysis with $\mathrm{P}$ values $<0.1$ were incorporated into the multivariate logistic regression analysis. This cut-off was set to include a limited number of variables in the logistic regression model, as the number of outcomes (death in the ICU) was relatively small $(n=30)$. The OR and $95 \%$ CI were calculated for all significant qualitative variables in univariate analysis, and all significant variables in multivariate analysis. Potential interactions were tested, and the Hosmer-Lemeshow goodness-of-fit was calculated. The multivariable model was considered as accurate if $\mathrm{p}$ value of the Hosmer-Lemeshow test was not significant.

In order to determine the impact of hyperoxemia on morbidity, MV-free days, length of ICU stay, SOFA score at VAP diagnosis were compared between patients who spent $>43 \%$ of time with hyperoxemia to those who spent $\leq 43 \%$ of time with hyperoxemia. The threshold of $43 \%$ was selected because it was the median time spent with hyperoxemia during the 3 days preceding VAP diagnosis in all study patients.

\section{Results}

\section{Patient characteristics}

Five hundred forty-seven patients received invasive $M V$ for more than 48 hours during the study period. Ninety-three patients $(17 \%)$ developed at least one VAP episode and were all included in the study. The incidence rate of VAP was 11.7 VAP per 1,000 ventilator-days. Thirty patients with VAP (32\%) died in the ICU. Patient characteristics are presented in Tables 1,2.

\section{Risk factors for ICU-mortality}

\section{Univariate analysis}

Although age, and SOFA score at the day of VAP diagnosis were significantly lower, percentage of patients with appropriate antibiotic treatment was significantly higher in survivors, compared with nonsurvivors (Tables 1,2).

No significant difference was found in time spent with hyperoxemia at ICU admission, at VAP diagnosis, during the 7 days before VAP diagnosis, and the 7 days following VAP diagnosis between survivors and nonsurvivors (Figure 1).

\section{Multivariate analysis}

Age and SOFA score at VAP diagnosis were independently associated with higher risk for ICU mortality (Table 3). 
Table 1 Characteristics of study patients at ICU admission

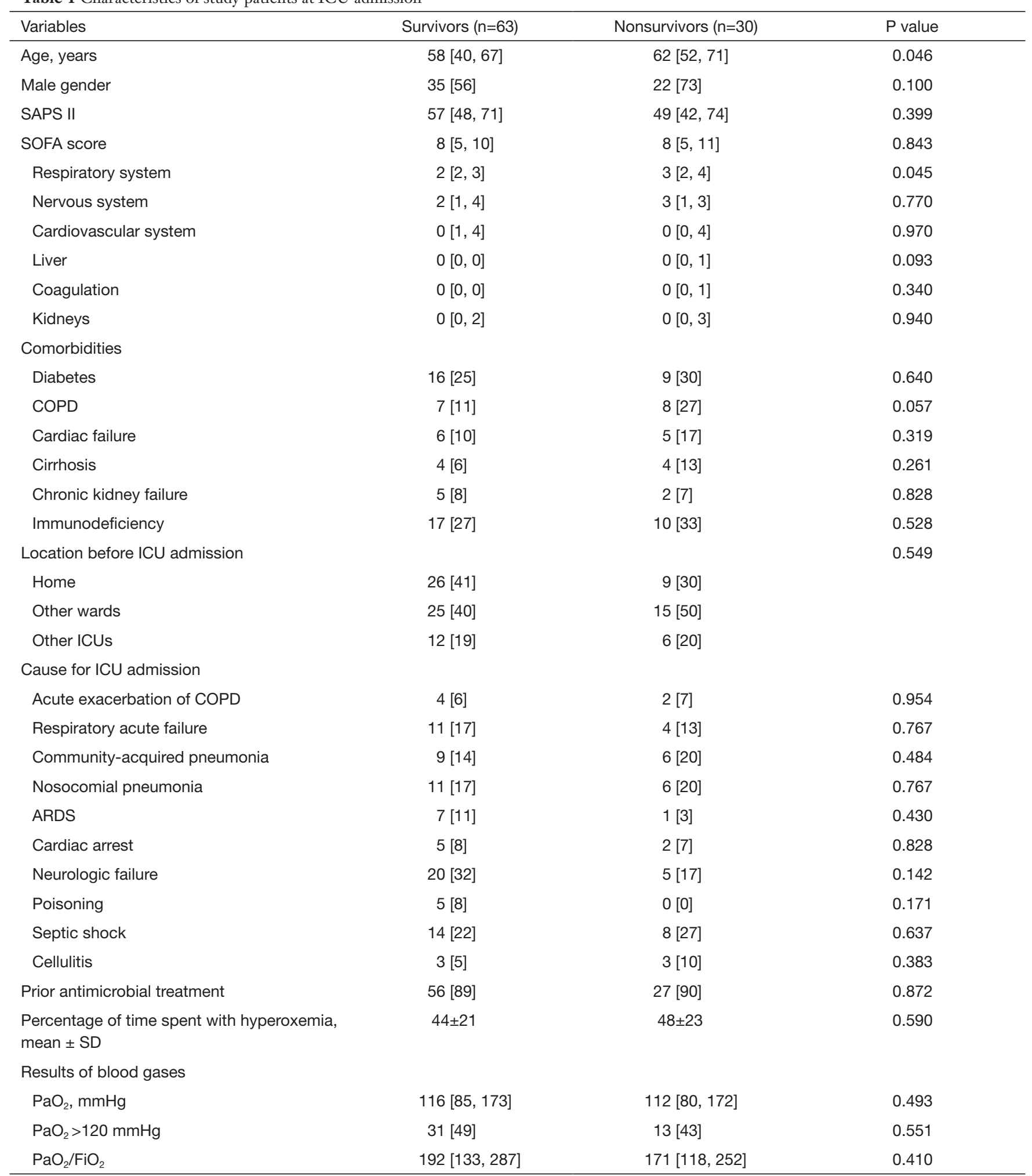

Data are presented as $\mathrm{n}[\%]$ or median [interquartile range], unless otherwise indicated. SAPS, simplified acute physiology score; SOFA, sequential organ failure assessment; COPD, chronic obstructive pulmonary disease; ICU, intensive care unit; ARDS, acute respiratory distress syndrome; $\mathrm{PaO} 2$, partial pressure of arterial oxygen; $\mathrm{FiO}_{2}$, fraction of inspired $\mathrm{O}_{2}$. 
Table 2 Patient characteristics during ICU stay

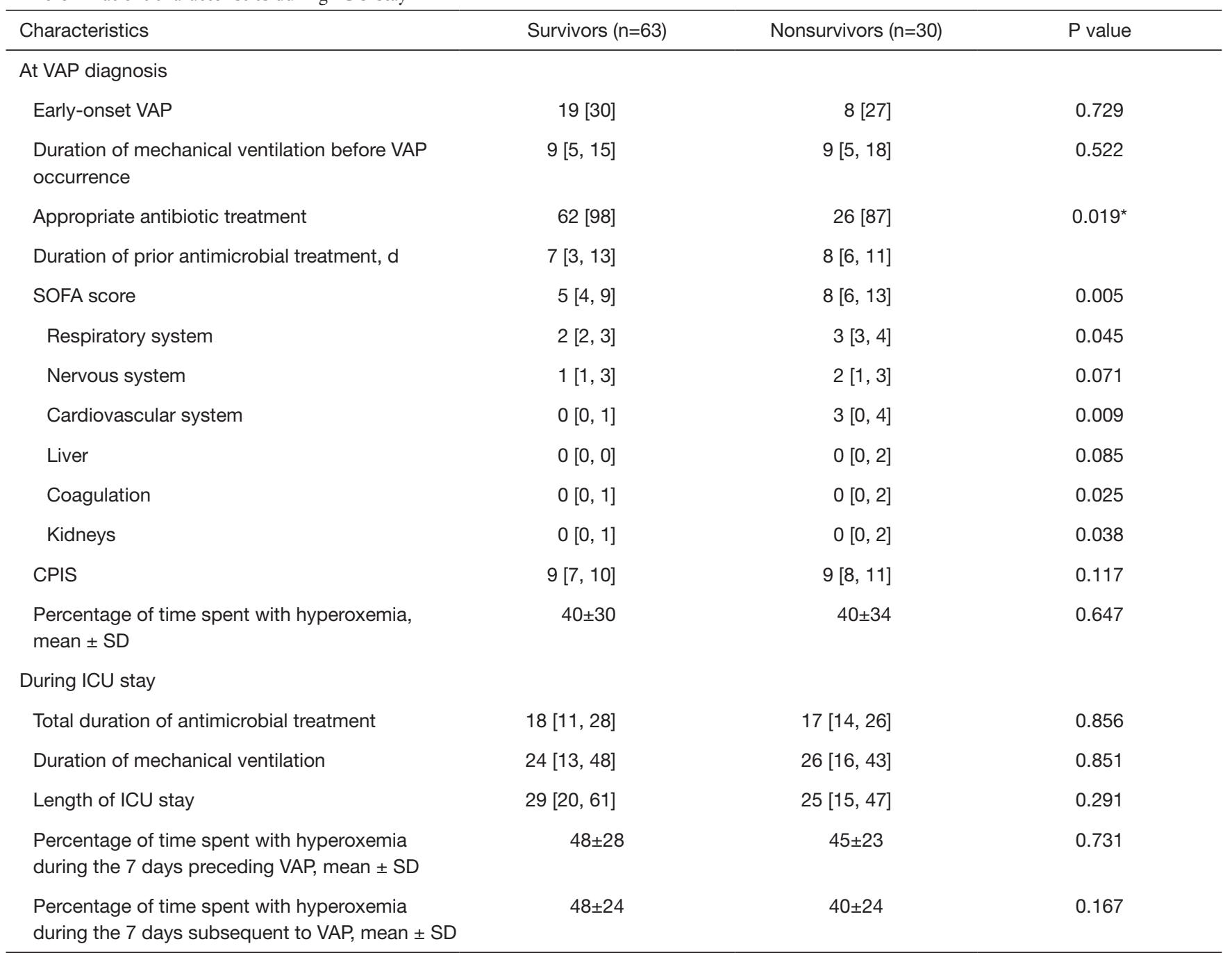

Data are presented as $\mathrm{n}[\%]$ or median [interquartile range], unless otherwise indicated. *, OR (95\% Cl): 0.10 (0.01-0.98). VAP, ventilatorassociated pneumonia; SOFA, sequential organ failure assessment; CPIS, clinical pulmonary infection score; ICU, intensive care unit.

\section{Impact of hyperoxemia on other outcomes}

No significant difference was found in SOFA score at the day of VAP diagnosis, total duration of MV, MV-free days, or ICU length of stay between patients who spent $>43 \%$ of time with hyperoxemia, and those who spent $\leq 43 \%$ of time with hyperoxemia during the 3 days preceding VAP occurrence (Table 4).

\section{Microbiological results}

VAP was polymicrobial in $15(16 \%)$ patients, and related to MDRB in $25(27 \%)$ patients. Gram-negative bacteria represented $78 \%$ of all bacteria, and were identified in $75 \%$ of VAP patients. P. aeruginosa (24\%), Klebsiella sp. (16\%), and S. aureus $(18 \%)$ were the most common bacteria in VAP patients (Table 5).

\section{Discussion}

In our study, hyperoxemia at ICU admission, or during ICU stay, was not significantly associated with ICU mortality in VAP patients. Similarly, hyperoxemia did not impact morbidity (duration of MV, MV-free days, SOFA score at VAP occurrence, and length of ICU stay) in these patients. Only age and SOFA score at the day of VAP occurrence 
were independently associated with higher risk for ICU mortality.

To our knowledge, our study is the first to evaluate the relationship between hyperoxemia and mortality in VAP

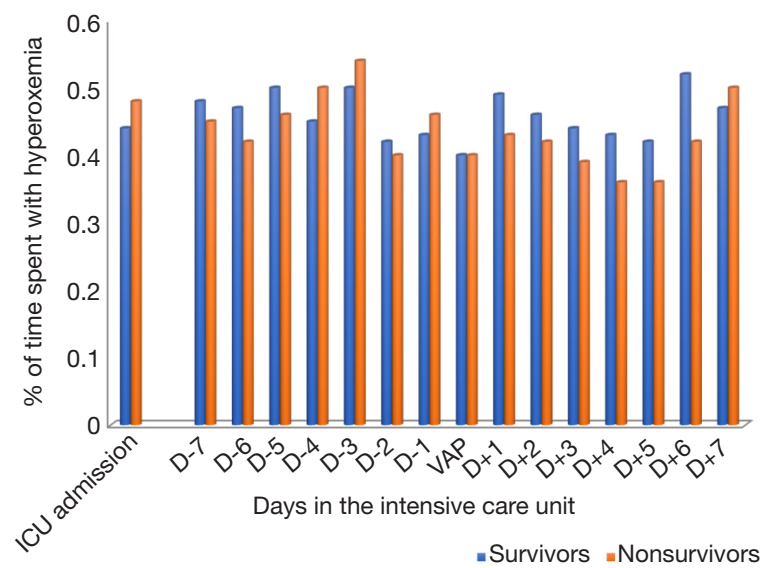

Figure 1 Relationship between hyperoxemia and ICU-mortality at ICU admission, and during ICU stay. $\mathrm{P}>0.2$ for all comparisons of mean percentage of time spent with hyperoxemia between survivors and nonsurvivors.

Table 3 Factors associated with mortality by multivariate analysis

\begin{tabular}{lcc}
\hline Factors & P value & OR $(95 \% \mathrm{Cl})$ \\
\hline Age & 0.019 & $1.04(1.01-1.08)^{\star}$ \\
SOFA & 0.003 & $1.19(1.06-1.34)^{\star \star}$ \\
Appropriate antibiotic & 0.081 & - \\
treatment & & \\
\hline
\end{tabular}

${ }^{*}$, per year; ${ }^{* *}$, per point of SOFA score. Hosmer-Lemshow goodness-of-fit, $P=0.932$. SOFA, sequential organ failure assessment; $\mathrm{OR}$, odds ratio, $\mathrm{Cl}$, confidence interval. patients. One could argue that hyperoxemia would have resulted in more severe pulmonary lesions in patients with VAP, and higher mortality rates. Previous studies have clearly shown the negative impact of hyperoxemia on the lung, and described HALI $(11,13,15,16,22,23)$. However, no significant relationship was found between hyperoxemia and mortality in this cohort of VAP patients.

The definition used for hyperoxemia was based on an arbitrary threshold and could be a matter for debate, as no consensus exists on the definition of this condition. However, the definition used in our study was rather stringent and the mean daily time spent with hyperoxemia $(45 \%)$ was in line with that reported by a recent multicenter study (59\%) (2). Recent interventional studies also used the threshold of $\mathrm{SpO}_{2} \geq 98 \%$ to define hyperoxemia $(12,24-26)$. Only one $\mathrm{SpO}_{2}$ value per hour was collected and we considered this value as a surrogate for the whole hour. This might have influenced the reliability of our analysis. However, this approximation could probably reflect the daily hyperoxemia exposure. In addition, no significant difference was found in percentage of patients with hyperoxemia, defined as $\mathrm{PaO}_{2}>120 \mathrm{mmHg}$, at ICU admission between survivors and nonsurvivors. The arbitrary threshold of $43 \%$ of time spent with hyperoxemia was used to determine the impact of hyperoxemia on secondary outcomes. Different results would have been obtained if $\mathrm{PaO}_{2}$ values have been used. However, all analyses were repeated using a more stringent threshold for percentage of time spent with hyperoxemia $\left(>75^{\text {th }}\right.$ quartile) at ICU admission, at VAP diagnosis, during the 7 days preceding or following VAP. Similar results were found regarding the relationship between hyperoxemia, mortality or secondary outcomes (data not shown). In a large multicenter cohort study, a dose-response relationship was found between supraphysiological arterial oxygen levels and

Table 4 Impact of hyperoxemia on secondary outcomes

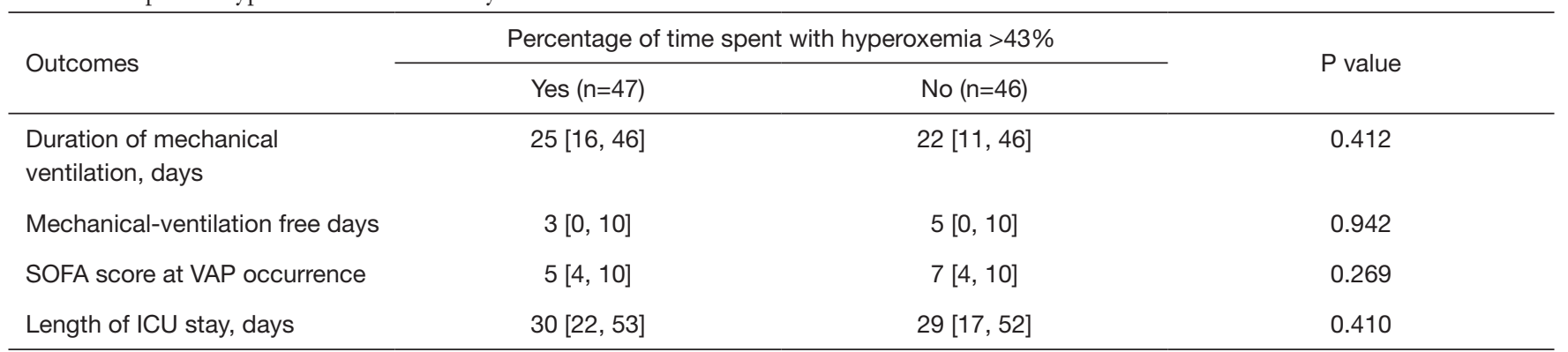

Data are presented median [interquartile range]. SOFA, sequential organ failure assessment; VAP, ventilator-associated pneumonia; ICU, intensive care unit. 
Table 5 Microorganisms responsible for ventilator-associated pneumonia

\begin{tabular}{lc}
\hline Microorganisms & Value $(\mathrm{n}=116)$ \\
\hline Gram-negative bacilli & $91[78]$ \\
Pseudomonas aeruginosa & $28[24]$ \\
Klebsiella sp. & $18[16]$ \\
Escherichia coli & $11[9]$ \\
Enterobacter sp. & $9[8]$ \\
Stenotrophomonas maltophilia & $6[5]$ \\
Heamophilus influenzae & $6[5]$ \\
Serratia sp. & $3[3]$ \\
Proteus mirabilis & $3[3]$ \\
Acinetobacter baumannii & $2[2]$ \\
Citrobacter sp. & $2[2]$ \\
Moraxella catarrhalis & $1[1]$ \\
Morganella morganii & $1[1]$ \\
Burkholderia dolosa & $1[1]$ \\
Gram-positive cocci & $17[15]$ \\
Methicillin-sensitive S. aureus & $13[11]$ \\
Methicillin-resistant S. aureus & $4[3]$ \\
\hline Results are presented as n &
\end{tabular}

Results are presented as $\mathrm{n}[\%]$.

hospital mortality, ICU mortality, and MV-free days (11). The effect size was influenced by the definition of arterial hyperoxia, and severe hyperoxia was associated with poor outcomes.

A large number of patients included in our study had pulmonary lesions at ICU admission. Therefore, the impact of hyperoxemia on mortality could have been confounded by this factor. However, subgroup analyses of patients with or without acute lung injury at ICU admission showed similar results (data not shown). The median time from admission to VAP occurrence was relatively long (9 days). Therefore, the impact of hyperoxemia at ICU admission on mortality could have been reduced. Several previous studies showed that the negative impact of hyperoxemia on outcome was higher during the first $24 \mathrm{~h}$ after ICU admission, when acute illness is more severe, compared with subsequent period of $M V$ and critical illness. The number of included patients $(\mathrm{n}=93)$ was relatively small. Therefore, larger studies are required to evaluate the relationship between hyperoxemia and mortality in VAP patients.

Several animal studies highlighted the relationship between hyperoxemia and VAP, and suggested that it could be related to an alteration of phagocytosis and innate immunity via molecular mechanisms and increased inflammatory response $(19,27,28)$. In fact, in animals exposed to hyperoxemia ROS mediate both direct and indirect modulation of signaling molecules such as protein kinases, transcription factors, receptors, and pro- and antiapoptotic factors (29). However, several aspects are unclear. Is it a concentration or a time dependent phenomenon? When hyperoxic injury is the most deleterious? How to differentiate lung injury related to MV from that associated to hyperoxemia? A better understanding of the signaling pathways leading to HALI would be helpful to in improving prevention and treatment of VAP.

Animal studies showed that macrophage impairment can be restored by antioxidants, and that molecular mechanism of cellular protection could be involved in the physiological response to supra-physiological exposure in ventilated patients $(30,31)$. In an animal study, in which animals were receiving hyperoxemia, ascorbic acid supplementation was associated with significant improvement of $P$. Aeruginosa clearance, and decreased levels of HMGB1, and reactive oxygen species in lung tissue (32).

In addition to the above-discussed limitations, our study was retrospective, and performed in a single center. Therefore, our results could not be generalized to other ICUs. However, the median time spent with hyperoxemia was in line with previous studies. In addition, all VAP episodes were prospectively identified. No data on ventilator settings, Murray score at VAP diagnosis, or on the correlation between $\mathrm{PaO}_{2}$ and $\mathrm{SpO}_{2}$ were available. Peripheral vasomotor disorders, low-flow, factors influencing the oxygen dissociation curve (temperature, $\mathrm{pH}$, $\mathrm{PaCO}_{2}$ ), motion-related artifacts, can alter the measurement of $\mathrm{SpO}_{2}$ (33). Further, there is heterogeneity in performance of various pulse oximetry devices in ICU, and pulse oximetry could overestimate arterial oxygen saturation. Bias tends to increase with rising lactate and hypoxia (34). However, there is no consensual definition for hyperoxemia in the literature. Further, $\mathrm{SpO}_{2} \geq 98 \%$ was used in several recent studies on hyperoxemia $(2,12,24-26)$.

\section{Conclusions}

Hyperoxemia at ICU admission, or during ICU stay, had no significant impact on ICU mortality in critically ill patients 
with VAP. Further larger multicenter studies are required to better assess the impact of hyperoxemia on mortality in patients with VAP.

\section{Acknowledgements}

None.

\section{Footnote}

Conflicts of Interest: S Nseir: MSD (lecture), and Ciel Medical (advisory board). This study was presented in part as an abstract at the congress of the French Society of Intensive Care, Paris 2017.

Ethical Statement: The IRB of the Lille University Hospital approved the study and waived informed consent

\section{References}

1. O'Driscoll BR, Howard LS, Bucknall C, et al. British Thoracic Society emergency oxygen audits. Thorax 2011;66:734-5.

2. Suzuki S, Eastwood GM, Peck L, et al. Current oxygen management in mechanically ventilated patients: a prospective observational cohort study. J Crit Care 2013;28:647-54.

3. Suzuki S, Eastwood GM, Glassford NJ, et al. Conservative oxygen therapy in mechanically ventilated patients: a pilot before-and-after trial. Crit Care Med 2014;42:1414-22.

4. Helmerhorst HJ, Schultz MJ, van der Voort PH, et al. Effectiveness and Clinical Outcomes of a Two-Step Implementation of Conservative Oxygenation Targets in Critically Ill Patients: A Before and After Trial. Crit Care Med 2016;44:554-63.

5. Cornet AD, Kooter AJ, Peters MJL, et al. The potential harm of oxygen therapy in medical emergencies. Crit Care 2013;17:313.

6. Martin DS, Grocott MPW. Oxygen therapy in critical illness: precise control of arterial oxygenation and permissive hypoxemia. Crit Care Med 2013;41:423-32.

7. Farquhar $\mathrm{H}$, Weatherall $\mathrm{M}$, Wijesinghe $\mathrm{M}$, et al. Systematic review of studies of the effect of hyperoxia on coronary blood flow. Am Heart J 2009;158:371-7.

8. Motoyama T, Okamoto K, Kukita I, et al. Possible role of increased oxidant stress in multiple organ failure after systemic inflammatory response syndrome. Crit Care Med 2003;31:1048-52.
9. Helmerhorst HJ, Roos-Blom MJ, van Westerloo DJ, et al. Association Between Arterial Hyperoxia and Outcome in Subsets of Critical Illness: A Systematic Review, MetaAnalysis, and Meta-Regression of Cohort Studies. Crit Care Med 2015;43:1508-19.

10. de Jonge E, Peelen L, Keijzers PJ, et al. Association between administered oxygen, arterial partial oxygen pressure and mortality in mechanically ventilated intensive care unit patients. Crit Care 2008;12:R156.

11. Helmerhorst HJF, Arts DL, Schultz MJ, et al. Metrics of Arterial Hyperoxia and Associated Outcomes in Critical Care. Crit Care Med 2017;45:187-95.

12. Girardis M, Busani S, Damiani E, et al. Effect of Conservative vs Conventional Oxygen Therapy on Mortality Among Patients in an Intensive Care Unit: The Oxygen-ICU Randomized Clinical Trial. JAMA 2016;316:1583-9.

13. Baleeiro CEO, Wilcoxen SE, Morris SB, et al. Sublethal hyperoxia impairs pulmonary innate immunity. J Immunol 2003;171:955-63.

14. Carvalho CR, de Paula Pinto Schettino G, Maranhão B, et al. Hyperoxia and lung disease. Curr Opin Pulm Med 1998;4:300-4.

15. Kallet RH, Matthay MA. Hyperoxic acute lung injury. Respir Care 2013;58:123-41.

16. Sinclair SE, Altemeier WA, Matute-Bello G, et al. Augmented lung injury due to interaction between hyperoxia and mechanical ventilation. Crit Care Med 2004;32:2496-501.

17. Jaffal K, Six S, Zerimech F, et al. Is hyperoxaemia a risk factor for ICU-acquired pneumonia? Lancet Respir Med 2017;5:e16.

18. Entezari M, Weiss DJ, Sitapara R, et al. Inhibition of highmobility group box 1 protein (HMGB1) enhances bacterial clearance and protects against Pseudomonas Aeruginosa pneumonia in cystic fibrosis. Mol Med 2012;18:477-85.

19. Patel VS, Sitapara RA, Gore A, et al. High Mobility Group Box-1 mediates hyperoxia-induced impairment of Pseudomonas aeruginosa clearance and inflammatory lung injury in mice. Am J Respir Cell Mol Biol 2013;48:280-7.

20. Six S, Jaffal K, Ledoux G, et al. Hyperoxemia as a risk factor for ventilator-associated pneumonia. Crit Care 2016;20:195.

21. American Thoracic Society; Infectious Diseases Society of America. Guidelines for the management of adults with hospital-acquired, ventilator-associated, and healthcareassociated pneumonia. Am J Respir Crit Care Med 2005;171:388-416. 
22. Tateda K, Deng JC, Moore TA, et al. Hyperoxia mediates acute lung injury and increased lethality in murine Legionella pneumonia: the role of apoptosis. J Immunol 2003;170:4209-16.

23. Makena PS, Luellen CL, Balazs L, et al. Preexposure to hyperoxia causes increased lung injury and epithelial apoptosis in mice ventilated with high tidal volumes. Am J Physiol Lung Cell Mol Physiol 2010;299:L711-9.

24. Panwar R, Hardie M, Bellomo R, et al. Conservative versus Liberal Oxygenation Targets for Mechanically Ventilated Patients. A Pilot Multicenter Randomized Controlled Trial. Am J Respir Crit Care Med 2016;193:43-51.

25. Asfar P, Schortgen F, Boisramé-Helms J, et al. Hyperoxia and hypertonic saline in patients with septic shock (HYPERS2S): a two-by-two factorial, multicentre, randomised, clinical trial. Lancet Respir Med 2017;5:180-90.

26. Nehme Z, Stub D, Bernard S, et al. Effect of supplemental oxygen exposure on myocardial injury in ST-elevation myocardial infarction. Heart 2016;102:444-51.

27. Raffin TA, Simon LM, Braun D, et al. Impairment of phagocytosis by moderate hyperoxia (40 to 60 per cent oxygen) in lung macrophages. Lab Invest 1980;42:622-6.

Cite this article as: Six S, Rouzé A, Pouly O, Poissy J, Wallet F, Preau S, Nseir S. Impact of hyperoxemia on mortality in critically ill patients with ventilator-associated pneumonia. Ann Transl Med 2018;6(21):417. doi: 10.21037/atm.2018.10.19
28. Entezari M, Javdan M, Antoine DJ, et al. Inhibition of extracellular HMGB1 attenuates hyperoxia-induced inflammatory acute lung injury. Redox Biol 2014;2:314-22.

29. Gore A, Muralidhar M, Espey MG, et al. Hyperoxia sensing: from molecular mechanisms to significance in disease. J Immunotoxicol 2010;7:239-54.

30. Morrow DM, Entezari-Zaher T, Romashko J 3rd, et al. Antioxidants preserve macrophage phagocytosis of Pseudomonas aeruginosa during hyperoxia. Free Radic Biol Med 2007;42:1338-49.

31. Arita Y, Kazzaz JA, Joseph A, et al. Antioxidants improve antibacterial function in hyperoxia-exposed macrophages. Free Radic Biol Med 2007;42:1517-23.

32. Patel VS, Sampat V, Espey MG, et al. Ascorbic Acid Attenuates Hyperoxia-Compromised Host Defense against Pulmonary Bacterial Infection. Am J Respir Cell Mol Biol 2016;55:511-20.

33. Jubran A. Pulse oximetry. Crit Care 2015;19:272.

34. Singh AK, Sahi MS, Mahawar B, et al. Comparative Evaluation of Accuracy of Pulse Oximeters and Factors Affecting Their Performance in a Tertiary Intensive Care Unit. J Clin Diagn Res 2017;11:OC05-OC08. 